COMMENTARY ON COVID-19 AND THE Food SySteM

\title{
COVID-19 responses: Food policy councils are "stepping in, stepping up, and stepping back"
}

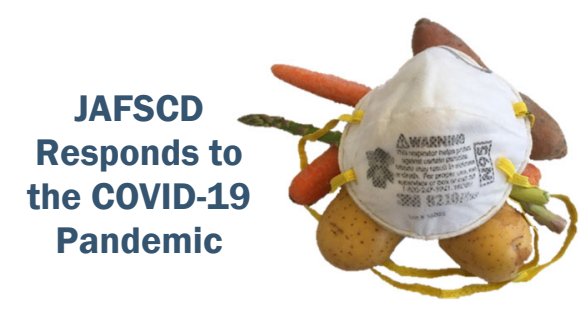

Anne Palmer ${ }^{a} *$

Johns Hopkins Center for a Livable Future

Abiodun T. Atoloye ${ }^{\mathrm{b}}$

University of Connecticut

Karen Bassarab c

Johns Hopkins Center for a Livable Future

\section{Larissa Calancie ${ }^{\mathrm{d}}$ \\ Tufts University}

Raychel Santo ${ }^{\mathrm{e}}$

Johns Hopkins Center for a Livable Future

\author{
Kristen Cooksey Stowers ${ }^{\mathrm{f}}$ \\ University of Connecticut
}

Submitted September 22, 2020 / Published online November 2, 2020

Citation: Palmer, A., Atoloye, A. T., Bassarab, K., Calancie, L., Santo, R., \& Cooksey Stowers, K. (2020). COVID-19

responses: Food policy councils are "stepping in, stepping up, and stepping back." Journal of Agriculture, Food Systems,

and Community Development, 10(1), 223-226. https://doi.org/10.5304/jafscd.2020.101.013

Copyright (C) 2020 by the Authors. Published by the Lyson Center for Civic Agriculture and Food Systems. Open access under CC-BY license.

\begin{abstract}
In the wake of the COVID-19 pandemic, food policy councils (FPCs) have emerged as a critical structure for organizing community-based responses to multiple food system issues. Strong relationships with

a * Corresponding author: Anne Palmer, Associate Scientist, Bloomberg School of Public Health, and Program Director, Johns Hopkins Center for a Livable Future, Baltimore, Maryland USA: +1-410-575-1076 or +1-443-608-9011; Apalmer6@jhu.edu

b Abiodun T. Atoloye, PhD, Postdoctoral Research Associate, Rudd Center for Food Policy and Obesity, University of Connecticut; abiodun.atoloye@uconn.edu

${ }^{\mathrm{c}}$ Karen Bassarab, Senior Program Officer, Johns Hopkins Center for a Livable Future, Bloomberg School of Public Health; Kbanks10@jhu.edu

d Larissa Calancie, PhD, Research Assistant Professor, ChildObesity180, Friedman School of Nutrition Science and Policy, Tufts University; Larissa.Calancie@,tufts.edu

e Raychel Santo, Senior Program Coordinator, Johns Hopkins Center for a Livable Future, Bloomberg School of Public Health; rsanto1@jhu.edu

${ }_{\mathrm{f}}^{\mathrm{f}}$ Kristen Cooksey Stowers, PhD, Assistant Professor of Health Disparities, University of Connecticut; Department of Allied Health Sciences; Rudd Center for Food Policy \& Obesity; Health Disparities Institute; kristen.cooksey@uconn.edu

Acknowledgements and Funding Disclosure

Authors of this publication are members of the Food Policy Council Working Group, part of the Nutrition and Obesity Policy Research and Evaluation Network (NOPREN). NOPREN is supported by Cooperative Agreement Number 5U48DP00498-05, funded by the Centers for Disease Control and Prevention's (CDC) Division of Nutrition, Physical Activity, and Obesity (DNPAO) and Prevention Research Centers Program. The findings and conclusions in this publication are those of the author(s) and do not necessarily represent the official position of the CDC or the U.S. Department of Health and Human Services (DHHS).
\end{abstract}


various food system stakeholders have proven essential in inspiring coordinated action. Using the early results of a Johns Hopkins Center for a Livable Future survey of FPCs (2020), we discuss some of the accomplishments and contributions that 118 FPCs have made toward addressing hunger and supporting producers, school food, food chain workers, racial equity, and resilience in the United States and in tribal nations.

\section{Keywords}

COVID-19, Pandemic, Food Policy Councils, Emergency Food, Food Insecurity, Hunger, Producers, School Food, Food Chain Workers, Racial Equity, Resilience

"We are taking care of everyone that has asked for help to the best of our ability."

\section{— From the Cass County (Iowa) Food Policy Council's survey, 2020}

In these unprecedented times, food policy councils ${ }^{1}$ (FPCs) have been thrust into roles beyond anything their members could have imagined. FPC members represent different food system sectors. Prior to COVID-19, they were working together and collaborating with other food system actors (e.g., producers, retailers, emergency food providers, public health practitioners) to educate stakeholders about food system issues, advocate for food and agriculture policies, mobilize residents to influence decision-makers, and advise governments and institutions on policy. As a result of the concurrent pandemic and structural racism crises, the convening role of FPCs has been crucial to their success in responding to the food and agricultural needs of their communities. During this time, FPCs have continued to fulfill the roles above and assumed new ones, all with a heightened urgency and seriousness.

We have witnessed many councils "stepping in, stepping up, and stepping back" because of their established relationships with food system actors in order to determine how they respond to both immediate and long-term needs in their communities. Below, we highlight several illustrative examples from FPCs across the U.S. and Tribal Nations that are transitioning from their pre-pandemic plans to prioritize emergency food assistance, link food producers to new markets, and take on other issues related to the crises. The examples below were collected as part of the Johns Hopkins Center for a Livable Future (CLF)'s annual census of FPCs (CLF, 2020); the latest version includes 20 questions relating to COVID-19. Responding to questions about their role or accomplishments in addressing COVID-19, these examples are either direct quotes or summaries of responses, and are grouped thematically below. This commentary reflects responses from 118 FPCs who completed the survey by July 21, 2020. A more comprehensive and in-depth analysis of responses is currently underway.

Emergency food assistance: The Lake County Food Access Coalition (Colorado) "came together with community members and organizations to create emergency feeding plans, a food pantry, and a food delivery service," open to all community members in this rural county. White Earth Food Sovereignty Initiative (Minnesota) is feeding community members, particularly older residents, while working to start a mobile grocery store that sells traditional native foods. The Dakota County Voices for Food (Nebraska) "raised and solicited over [US] $\$ 40,000$ in funds to address hunger, coordinated the distribution of 1,200 food boxes, and converted the county's food pantry to a drive-up model."

1 A food policy council is defined as an organized group of stakeholders from various sectors that may be sanctioned by a government body or may exist independently of government, which works to address food systems issues and needs at the local (city/municipality or county), state/provincial, regional, or Native American/First Nations levels through policy. 
Linking food producers to new markets: Lehigh Valley FPC (Pennsylvania) assisted in saving several farms that had lost their commercial accounts by helping them to divert their products to other retail outlets and by connecting producers directly to school and pantry programs to improve healthy food options. The South Coast FPC (Massachusetts) has distributed 30,000 Farmers-to-Families Food Boxes. Frederick County FC (Maryland) set up a secure online marketplace to sell and buy local food. High Desert Food \& Farm Alliance (Oregon) acquired funds to reimburse farmers for food donations.

Food security: The Marshall FPC (Indiana) has shared information with the public on Pandemic EBT ${ }^{2}$ (P-EBT) cards and helped change SNAP guidelines. The Jefferson County FPC (Colorado) worked with state partners to obtain a SNAP waiver for online ordering and delivery via Amazon and Walmart. The Montgomery County FPC (Maryland) is "coordinating the food assistance response of 100+ emergency food providers, connecting local food producers and farms to the food security response efforts, [and] advocating for enhanced food security measures (expanded SNAP, P-EBT, summer meals, etc.) to support food access." Eat Well Crawford County (Kansas) worked to get permission from funders to utilize current grant funds to address food insecurity resulting from COVID-19, particularly in rural communities.

School food: The Adams County FPC (Pennsylvania) arranged weekly phone calls with public schools to share plans, discuss delivery options, identify gaps and available resources, and use the backpack program to fulfill needs. Syracuse-Onondaga Food Systems Alliance (New York) co-hosted a convening of school food service professionals "to celebrate their work in the face of the crisis and identify opportunities to build connections to ensure students have the food they need even as schools are closed." Chatham Community Food Council (North Carolina) facilitated discussions among emergency summer food providers to streamline needs and fill gaps.

Food chain workers: The Detroit FPC (Michigan) successfully advocated for funds to provide personal protective equipment (PPE) for grocery workers. The Rhode Island FPC called on the governor to designate grocery clerks and stockers, fast food workers, food hub workers, and school meal preparers as Tier 2 emergency workers, which would provide access to free childcare. Western Michigan Food Recovery Council highlighted the disproportionate impacts of COVID-19 faced by Black, Indigenous, People of Color (BIPOC) communities, which led to recommendations to the state for more PPE and protection for front-line food workers.

Racial equity: Philadelphia FPC (Pennsylvania) is hosting monthly gatherings "to explore and initiate COVID-19 responses that address root causes (racism and oppression), foster collaboration across the food system, and work towards a more just Philadelphia where all people have the power to access, own and control their food, land and labor." Greater Nashua Food Council (New Hampshire) is holding conversations on racial equity with 20 to 25 active organizations, government officials, and community members, and will be holding a training about becoming a more culturally effective organization. As data about massive racial disparities in the health and economic impacts of COVID-19 began surfacing, the Greater Kansas City Food Policy Coalition (Kansas and Missouri) sought to engage stakeholders, such as

2 Pandemic EBT program was authorized in the Families First Coronavirus Response Act. It provides food assistance for non-SNAP households to offset meals costs that children would have received at school, and also provides a supplement for current SNAP households. 
meat factory workers, in developing appropriate policy responses. Doing so prompted the Coalition to start exploring immediate and long-term changes to increase BIPOC and low-wage food chain workers' participation and leadership in the Coalition.

Policy: In Jefferson County (Colorado), the FPC meets weekly to share and discuss on-the-ground needs, local and state food policy, and additional updates among partners, city managers, city mayors, county commissioners, and additional decision-makers. Knoxville-Knox County FPC (Tennessee) serves as the primary contact for food-related issues for the city and county Emergency Operations Center. Grow Montana FPC successfully advocated for farmers markets to be considered essential businesses during the state's mandated lockdown. San Diego Food Systems Alliance (California) developed a COVID-19 food policy platform for all levels of governments.

Resiliency: While community needs remain urgent, several groups (Prince George's County Food Equity Council, Maryland; Humboldt FPC, California; Baltimore Food Policy Initiative, Maryland; Hartford Advisory Commission on Food Policy, Connecticut; Montgomery County Food Council, Maryland) are working on resilience strategies to weather future disruptions to their communities and food systems. Austin-Travis County Food Policy Board (Texas) is highlighting how the pandemic underscores the systemic change needed in the local food system.

Key to strengthening and sustaining FPCs' efforts to address the dual COVID-19 and structural racism crises in the U.S. will be learning from and supporting leadership of people from low-income communities and communities of color, who have successfully organized for decades during times of crises. Many councils are heavily represented by professional white women who may struggle to meaningfully engage community members who are most affected by inequities in the food system, who frequently are BIPOC. Recently, as more councils recognize the manifestation of racism throughout every facet of society, they also acknowledge and are acting upon the need to modify their councils' principles and practices to more explicitly reflect core values such as racial equity, food justice, and food sovereignty. In this sense, councils are "stepping back" to examine how they can support low income and BIPOC engagement, participation, and leadership in councils and in their communities more broadly.

What was presumed to be a few months of uncertainty and disruption as COVID-19 first took hold in the U.S. is evolving into a reorganization of our country's social and economic systems - systems that have been failing many communities for years, as has been seen in the heightened exposure of structural racism. Building new systems from the ground up means lifting up what is working, attending to the trauma that was already present, and preparing for the long-term transformation that is needed to address structural racism, classism, and other -isms in this country. FPCs across the country are doing their best to build on their core strength of acting as conveners of entities across the food system to build partnerships, coordinate resources, and inform decision-makers about the policy needs of their communities. In order to sustain and strengthen their responses to COVID-19, councils need platforms for sharing strategies that work; fast, reliable local data to understand community needs; and resources to support the people and initiatives that make FPCs effective.

\section{Reference}

Johns Hopkins Center for a Livable Future (CLF). (2020). Food policy council census [Data file]. Retrieved 21 July 2020. 